\title{
Phonological awareness and sinusoidal amplitude modulation in phonological dislexia
} Conciencia fonológica y la modulación sinusoidal de la amplitud en la dislexia fonológica Yolanda Peñaloza-López', Aline Herrera-Rangel', Santiago J. Pérez-Ruiz², Adrián Poblano³

\begin{abstract}
Objective: Dyslexia is the difficulty of children in learning to read and write as results of neurological deficiencies. The objective was to test the Phonological awareness (PA) and Sinusoidal amplitude modulation (SAM) threshold in children with Phonological dyslexia (PD). Methods: We performed a case-control, analytic, cross sectional study. We studied 14 children with PD and 14 control children from 7 to 11 years of age, by means of PA measurement and by SAM test. The mean age of dyslexic children was 8.39 years and in the control group was 8.15. Results: Children with PD exhibited inadequate skills in PA, and SAM. We found significant correlations between PA and SAM at 4 Hertz frequency, and calculated regression equations that predicts between one-fourth and one-third of variance of measurements. Conclusion: Alterations in PA and SAM found can help to explain basis of deficient language processing exhibited by children with PD.
\end{abstract}

Keywords: dyslexia; phonologic dyslexia; phonologic awareness; sinusoidal amplitude modulation.

\section{RESUMEN}

Objetivo: La Dislexia es la dificultad en niños de aprender a leer y escribir como resultado de una deficiencia neurológica. Nuestro objetivo fue probar la Conciencia fonológica (CF) y la Modulación sinusoidal de la amplitud (MSA) en niños con Dislexia fonológica (DF). Métodos: Realizamos un estudio analítico, transversal, de casos y controles. Estudiamos la CF y la MSA en 14 niños con DF y 14 controles de 7-11 años. La edad media de los niños con DF fue de 8.39 años y de los controles fue 8.15. Resultados: Los niños con DF presentaron deficiencias en CF y en MSA. Encontramos correlaciones entre CF y MSA en la frecuencia de 4 Hertzios (Hz), calculamos ecuaciones de regresión que predijeron de un cuarto a un tercio de la varianza de las mediciones. Conclusión: Las deficiencias en CF y en MSA pueden ayudar a comprender las alteraciones en el procesamiento del lenguaje presentadas por los niños con DF.

Palabras clave: dislexia; dislexia fonológica; conciencia fonológica; modulación sinusoidal de la amplitud.

Dyslexia refers to the difficulty experienced by some children in learning to read and write, presumably as the result of neuropsychological deficiencies not associated with other neurological alterations ${ }^{1,2}$. Phonologic dyslexia (PD) is a subtype of dyslexia characterized by main deficits in phonological analysis of the language $\mathrm{e}^{3,4}$.

Phonologic awareness (PA) is the linguistic ability that results from the knowledge that speech is composed of syllables and phonemes, and from the capability to fragment and reassemble words ${ }^{5,6}$. Although, some studies on deficits in PA in children with PD have been performed ${ }^{6}$, there is a weak explanation of how these alteration results in reading deficiencies.

Communication systems (i.e. auditory system), transmit information between the source and receptor. Signal is transmitted in a band frequency which carries the information. Modulation is defined as the change of one feature of the carrier according to signal information, i.e., amplitude, or frequency. Sound rhythm organizes events in time and plays an important role in phonology and prosody perception of language. The next step of communication: speech intelligibility, is strongly influenced by the ability to process temporal and frequency modulations. PA may come from several psychoacoustic abilities; for example: Sinusoidal amplitude modulation (SAM). SAM consists of the subject determination of the threshold for detection of amplitude modulation characteristics of stimuli (Figure 1), and can be administered at different frequencies, i.e., at 4, 16, 64, and $256 \mathrm{Hertz}(\mathrm{Hz})$, within a wide band noise ${ }^{7}$. Developmental features of SAM have a characteristic course, different from other psychoacoustical abilities', and can be altered in PD.

Because, relationship of SAM with PA in children with dyslexia has not been well studied, we performed this study with the objective to test and correlate PA and SAM in children

${ }^{1}$ National Institute of Rehabilitation, Laboratory of Central Auditory Alterations Research, Mexico City, México;

${ }^{2}$ National University of Mexico, Center of Applied Sciences and Technological Development, Laboratory of Acoustics, Mexico City, México;

${ }^{3}$ National Institute of Rehabilitation, Laboratory of Cognitive Neurophysiology, Mexico City, México.

Correspondence: A. Poblano; Calzada Mexico-Xochimilco 289;14389; Mexico City, México; E-mail:drdyslexia@yahoo.com.mx

Conflict of interest: There is no conflict of interest to declare.

Received 18 March 2015; Received in final form 11 November 2015; Accepted 30 November 2015. 
A

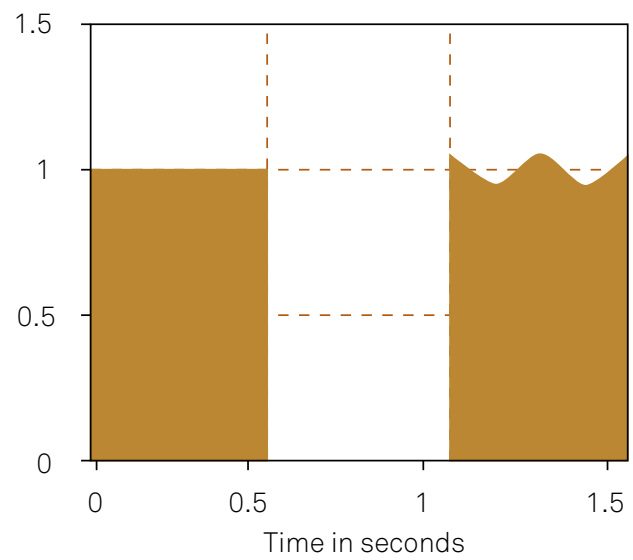

B

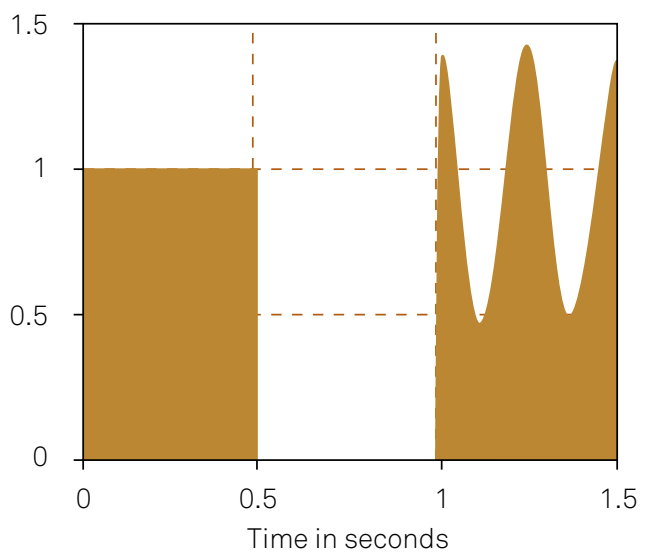

Figure 1. Sinusoidal amplitude modulation function. Panel at left (A) shows a no-modulated white-noise carrier and low-amplitude modulated sound. Panel at right (B) shows modulated white noise and high-amplitude modulated sound.

with PD by means of a specific psychoacoustic examination, searching if PD comprises an alteration of this specific neural network that underlie language analysis need for reading and writing $9,10,11$.

\section{METHODS}

\section{Subjects}

A highly selected group of children with PD were chosen and compared with a control group of healthy children of the same age and socioeconomic strata. We included subjects with specific dyslexia as recommended by the Diagnostic and Statistical Manual of Mental Disorders, version-IV (DSM-IV) ${ }^{12}$. A definition of dyslexia was considered when reading and word spelling in a child does not develop, or develop with greater difficulty, despite adequate socioeconomic environment and absence of neurological alterations ${ }^{1}$. Children with dyslexia met the following inclusion criteria: age between 7 and 11 years; with a delay of two years or more in their reading level (in México, most of children begin to learn reading at 5 years of age, in the Kindergarden last year) according to DSM-IV reviewed recommendations (F81.0 Reading disorder criteria). Each child subject demonstrating normal neurological examination; visual acuity equal or better than 20/20 index in the Snellen visual chart or corrected; normal pure-tone audiometry; adequate familial environment; come from a middle socio-economic stratum, score $\geq 90$ on the total Intelligence quotient (IQ) on Weschler intelligence scale for children (WISC-Revised version for México). Children with $\mathrm{PD}^{13}$, were selected from the Speech therapy department of the National Institute of Rehabilitation, Mexico City. No patients demonstrated attention deficit disorder, epilepsy, mental retardation, cerebral palsy, psychiatric disorders or other neurological signs, congenital malformations, or phoniatric alterations according to a complete clinic history. The control group was comprised of healthy children from a public school s, with the same age and socio-economic stratum. Each of the control children reads at current school grade level or better and demonstrated IQ $\geq 90$. No control subjects demonstrated evidence of neurological, ocular, hearing, genetic, speech, or psychiatric disorders. Controls were age- and gender-matched children. Moreover, they all exhibited good school performance (academic average, $>8$ of 10 points). We studied 14 children with PD and 14 control children. The mean age of the group of children with dyslexia was 8.39 years with a standard deviation (SD) of 1.13 years, while the mean age of children in the control group was 8.15 years $(\mathrm{SD}=1.36)$, no significant difference was observed between groups $(p>0.05)$, median in both groups was 8 years of age. In the group of children with PD and controls, 10 subjects were males (71\%) and four, females (29\%). All patients and controls subjects were right-handed: characteristics of children with PD, and controls is presented in Table 1. The protocol was approved by the Institutional Ethics and Research Board, and signed informed consent forms were obtained from the parents of the children according to Declaration of Helsinki recommendations.

\section{Neuro-linguistic examination}

Examination of neuro-linguistics variables in children with PD and controls included the following: phonemic synthesis; sounds counting; spelling; words counting; semantic speed; phonologic speed; no-sense words reading; syllable writing, and no-sense words writing ${ }^{14,15}$. Examination was carried-out by a senior specialist in Human Communication Disorders Medicine and their residents. Additionally, children in the study were examined by the WISC-R ${ }^{16}$, the Bender-gestaltic visuo-motor test ${ }^{17}$, and the Human figure drawing test ${ }^{18}$. All psychological tests were applied by a qualified psychologist in blind fashion. 
Table 1. Clinical characteristics of children with Phonological dyslexia (PD) and controls.

\begin{tabular}{lcc}
\hline Variable & Children with dyslexia & Controls \\
\hline School grade & $2^{\circ}-5^{\circ}$ & $2^{\circ}-5^{\circ}$ \\
\hline Family antecedent of dyslexia & $62 \%$ & $10 \%$ \\
Bender test (normal result) & $100 \%$ & $100 \%$ \\
Human drawing test (normal result) & $100 \%$ & $100 \%$ \\
\hline
\end{tabular}

\section{Sinusoidal amplitude modulation (SAM)}

Subjects participated in a 1 hour session in an isolated sound-proof room with adequate light and temperature. Participants performed a brief training session in order to decrease the children's anxiety. Children were seated in a comfortable position during the test. We administered the stimuli by means of TDH-49 headphones (Telephonics Co., Huntington, NY, USA), which were calibrated weekly according to American National Standards Institute (ANSI) recommendations. Stimuli consisted of a sinusoidal amplitude modulated sound in four frequencies: 4, 16, 64, and $256 \mathrm{Hertz}(\mathrm{Hz})$ (Figure 1) and a white-noise no-modulated noise carrier signal. We used the following equation for modulation calculation: $s(t)=\mathrm{c}\left[1+m \sin \left(2 \pi F_{\mathrm{m}}\right)\right] n(t)$, where $m$ is the deep of modulation, $(0 \leq \mathrm{m} \leq 1), F_{\mathrm{m}}$ is modulation frequency $(4,16,64$, and $256 \mathrm{~Hz}$ ) and $n(t)$ is noise carrier of stimuli with a compensation factor. Each sound lasts 500 milliseconds (msec), with $2.5 \mathrm{msec}$ of rise- and fall-time. Time between each stimuli was $500 \mathrm{msec}$. Stimuli were presented bi-aurally at 75 decibels $(\mathrm{dB}$, Hearing level [HL]) intensity, beginning at a modulation range of $2 \mathrm{~dB}$. The task was discriminate between serial presentations of two stimuli at different modulation level, and say whether the stimuli were the "same" or "different"18. Examiner began the test by selecting one modulation frequency, the stimuli were presented in a descending or ascending randomized manner to avoid any bias. If the stimuli were correctly identified, the modulation intensity decrease, thus, the modulation becomes more subtle. Threshold response was determined as the lowest amplitude in the dB-HL that could be perceived by the subject, next examiner change for the other frequencies.

\section{Statistics}

After the test, the data were pooled in a calculation sheet. Central and dispersion measurements were determined for quantitative variables and were compared by the Student t-test. We corrected for probability inflation due to multiple testing with the Bonferroni procedure. In this case, to achieve Bonferroni corrected probability criteria for $\mathrm{p} \leq 0.05$, the probability had to be $\leq 0.005$. Moreover, we performed a Pearson correlation calculation between PA measurement and SAM function; afterward, we constructed scattergrams of each significant correlation, and verified one-by-one for dots distribution in order to identify the true from wrong correlations and avoid statistical artifacts. We also calculated regression equations and the $r^{2}$ measurement of each significant correlation.

\section{RESULTS}

\section{General data}

TotalIQin the group of children withPD was $95.3 \pm 13.7$ points, mean Verbal IQ was $87.9 \pm 16.4$, and mean Executive IQ was $100.2 \pm 16.6$; while in control children Total IQ was 102.1 \pm 7.9 , Verbal IQ was 101.1 \pm 8.5 , and Executive IQ was $102.9 \pm 8.4$.

\section{Neuro-linguistic examination}

We observed lower performance in all subtests in the group of children with PD, when their results were compared with those of the control children. The differences were statistically significant (Table 2).

\section{Temporal transference modulation function}

In SAM measurements, we observed disadvantaged values in children with PD with respect to controls. We disclosed statistically significant differences in the $4 \mathrm{~Hz}$ frequency, and none in the remaining frequencies (Table 3).

\section{Correlations between phonological awareness (PA) and sensitivity-of-amplitude-modulation (SAM) function}

We found several significant correlations between SAM and PA measurements (Table 4). One example of a typical correlation is presented in a scattergram (Figure 2). SAM threshold at $4 \mathrm{~Hz}$ correlated with Phonemic synthesis, Sounds counting, Spelling, and No-sense words writing. Regression equations and $r^{2}$, showed that between one-fourth to one-third of variance could be predicted by these equations (0.28-0.31) (Table 5).

\section{DISCUSSION}

\section{Main findings}

The main contributions of our research were disclose that children with PD exhibit inadequate PA and SAM skills when were compared with the performance of the healthy control group; moreover, we found significant correlations between PA and SAM determinations at $4 \mathrm{~Hz}$. We calculated equations that predict correlations between SAM and measurements of PA, and $r^{2}$ values obtained from our data help to explain nearly one-fourth to one-third of the variance of results. In base to this results, we hope that in 
Table 2. Neuro-linguistic skills performance comparison in children with Phonological dyslexia (PD) and controls.

\begin{tabular}{|c|c|c|c|c|}
\hline \multirow{2}{*}{ Variable } & Children with dyslexia & Controls & \multirow{2}{*}{$\mathrm{t}$} & \multirow{2}{*}{$\mathrm{p}$} \\
\hline & $\mathrm{x} \pm \mathrm{SD}$ (range) & $\mathrm{x} \pm \mathrm{SD}$ (range) & & \\
\hline Phonemic synthesis & $14.9 \pm 17.4(10-50)$ & $88.0 \pm 5.2(85-95)$ & 15.0 & 0.001 \\
\hline Sound counting & $17.2 \pm 21.6(10-50)$ & $67.5 \pm 15.2(60-85)$ & 7.1 & 0.001 \\
\hline Spelling & $21.2 \pm 27.2(15-55)$ & $81.3 \pm 14.5(75-100)$ & 7.3 & 0.001 \\
\hline Word counting & $15.2 \pm 17.0(10-20)$ & $63.0 \pm 27.2(55-95)$ & 5.58 & 0.001 \\
\hline Semantic speed & $32.5 \pm 27.9(25-60)$ & $62.2 \pm 18.5(55-85)$ & 3.2 & 0.001 \\
\hline Phonological speed & $44.3 \pm 28.8(30-65)$ & $85.2 \pm 20.3(70-100)$ & 4.08 & 0.001 \\
\hline No-sense word reading & $30.2 \pm 26.6(20-60)$ & $71.0 \pm 10.7(65-80)$ & 5.31 & 0.001 \\
\hline Syllable writing & $18.2 \pm 23.0(15-30)$ & $70.7 \pm 6.0(65-80)$ & 8.29 & 0.001 \\
\hline No-sense word writing & $28.6 \pm 30.0(20-55)$ & $81.5 \pm 8.5(75-90)$ & 6.28 & 0.001 \\
\hline
\end{tabular}

X: mean; SD: Standard deviation; $\mathrm{p}$-values were Bonferroni corrected.

Table 3. Comparison of the mean of Sinusoidal amplitude modulation (SAM) threshold (dB) by frequency in children with Phonological dyslexia (PD) and control group children.

\begin{tabular}{lcccc}
\hline \multirow{2}{*}{ Frequency } & Children with dyslexia & Controls & $t$ & t \\
\cline { 2 - 3 } & $\mathbf{x} \pm \mathbf{S D}$ (range) & $\mathbf{x} \pm$ SD (range) & 4.7 & 0.001 \\
\hline $4 \mathrm{~Hz}$ & $14.1 \pm 4.6(10-20)$ & $7.4 \pm 2.4(4-10)$ & 2.3 & 0.20 \\
$16 \mathrm{~Hz}$ & $14.5 \pm 2.5(12-18)$ & $11.8 \pm 3.3(10-16)$ & 0.9 & 0.34 \\
$64 \mathrm{~Hz}$ & $14.7 \pm 5.0(10-20)$ & $13.1 \pm 3.5(10-18)$ & 1.9 & 0.6 \\
\hline $256 \mathrm{~Hz}$ & $19.1 \pm 6.3(14-26)$ & $14.8 \pm 5.3(10-20)$ & & \\
\hline
\end{tabular}

X: mean; SD: Standard deviation; dB: Decibels; $\mathrm{p}$-values were Bonferroni corrected.

Table 4. Significant correlations between Phonological awareness (PA) and Sinusoidal amplitude modulation (SAM) at $4 \mathrm{~Hz}$.

\begin{tabular}{ccccc}
\hline & Phonemic synthesis & Sound counting & Spelling & Syllable writing \\
\hline$r$ & 0.53 & 0.55 & 0.42 & 0.52 \\
$p$ & 0.004 & 0.002 & 0.004 & 0.004 \\
\hline
\end{tabular}

Table 5. Regression equations predicting correlations between Phonological awareness (PA) and Sinusoidal amplitude modulation (SAM) at $4 \mathrm{~Hz}$ and quadratic $r$.

\begin{tabular}{lcc} 
& Equation & $\mathbf{r}^{2}$ \\
\hline Phonemic synthesis & $7.46+0.93 \times$ phonemic synthesis & 0.28 \\
Sound counting & $5.4+1.16 \times$ sound counting & 0.31 \\
Spelling & $6.66+0.90 \times$ spelling & 0.18 \\
Syllable writing & $4.13+1.15 \times$ syllable writing & 0.28 \\
\hline
\end{tabular}

future, study of psychoacoustical performance (including SAM test), could help to an early identification, even during subclinical stage, of children with PD.

\section{Comparison with other studies}

Dyslexia was found to be associated with alteration in working memory, including the phonologic-linguistic subsystem $^{9}$. Later, other authors found alterations in the binaural fusion, and in the filtered words tests in children with dyslexia ${ }^{11}$. We decided to continue searching the possible alterations in phonologic analysis in children with PD.

Neuro-linguistic examination was abnormal in children with PD; the four sub-test linked with PA: phonemic synthesis, sound counting, spelling, and word counting showed significant lower values in children with PD. Semantic speed, showed also a decreased values in children with $\mathrm{PD}$, this 


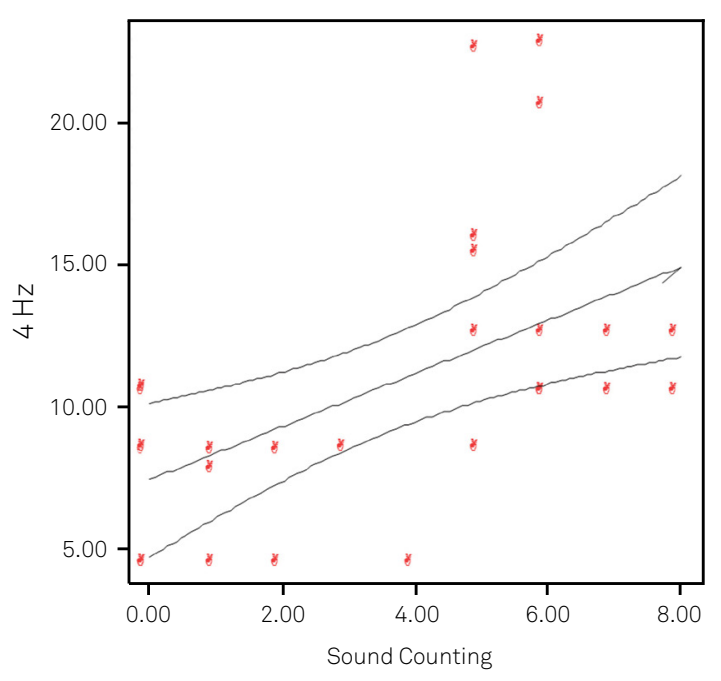

Figure 2. Scattergram depicting an example of typical significant correlation disclosed with regression line and Confidence interval $(95 \% \mathrm{Cl})$, in this case between threshold of sinusoidal modulation at $4 \mathrm{~Hz}$ (vertical line) and sound counting (horizontal line).

can be a secondary effect of the phonological deficit. Brooks et al. observed that the executive functions in children with reading disorders was altered ${ }^{20}$, this observation is in partial agreement with our data, and underline the executive dysfunction as one of the symptoms in PD.

Two papers had reported data of alterations in SAM in children with dyslexia. In the first study, Lorenzi et al. ${ }^{21}$ conducted a study in six children with dyslexia, six control children and six control adults. SAM thresholds were similar in normal children and adults. For both normal groups, Temporal modulation transfer functions (TMTF) were scored as low-pass in shape and showed low between-listener variability. TMTF measured in children with dyslexia showed higher between-listener variability as follows: TMTF were normal band-pass in two children, flat in one child, and as low pass in the remaining three children. Overall, SAM thresholds were abnormal in children with dyslexia at modulated frequencies of 4 and 1,024 Hz. Unprocessed-speech identification performance was nearly perfect in normal children and adults, and impaired in children with dyslexia. The authors noted that: "speech-envelope noise identification performance was poorer in normal children and in children with dyslexia than in normal adults. Performance improved across sessions in normal children and adults, but remained constant in children with dyslexia". In conclusion, in this research, when compared with control children, children with dyslexia exhibited poorer perception of voicing, manner, and place of articulation for unprocessed speech and poorer reception of voicing for "speech-envelope noise", however this research was performed with a short sample. Data from this observation, partially support our results because we also observed differences between children with dyslexia and controls at $4 \mathrm{~Hz}$ frequency. However, other differences between observations, can be attributed that our children with dyslexia were only of the phonological subtype.

In a second study, authors measured the detection of SAM thresholds, and discrimination thresholds of SAM depth, in addition to SAM rate. Each threshold was measured at slow and fast SAM rates of 4 and $128 \mathrm{~Hz}$, respectively. On overall, SAM thresholds were abnormal in children with dyslexia at both rates. The strongest deficit was observed again at $4 \mathrm{~Hz}$ in the SAM task, but a deficit was also apparent at $128 \mathrm{~Hz}$. These results reveal that, in addition to the reduced audibility of the slow and fast envelope cues, some children with dyslexia display poor encoding fidelity for these cues ${ }^{22}$.

Poelmans et al., investigated sensitivity to frequency modulation, amplitude rise-time, speech in noise perception, and PA in children with dyslexia. They disclosed less sensitive to slow-rate dynamic auditory processing, speech in noise perception, PA, and literacy abilities in children with dyslexia than controls ${ }^{23}$. In other study of the same authors, carried-out in adults with dyslexia, researchers found deviant phonemic rate responses of the Auditory steady state responses ${ }^{24}$. Other research found abnormalities in auditory tasks, and phonological processing, suggesting that individuals with dyslexia had deficits in the extent to which each of auditory and phonological factors are expressed and interact with environment and higher order cognitive influences ${ }^{25}$. Flaugnacco et al. studied a group of children with dyslexia by means of neuropsychological, psychoacoustic, and musical tests, testing temporal abilities. They found a strong link between several temporal skills, phonological and reading abilities, suggesting a particular link among rhythm processing in music and language ${ }^{26}$. The above quoted researches and data obtained from the present investigation, reinforce the idea that children with PD may have abnormal psychoacoustic abilities that alter their PA. Despite differences in methodology and patient selection among the researches, data are in the same direction of our results.

One possible explanation of deficiency in SAM detection at $4 \mathrm{~Hz}$, and no for the others frequencies, is that the turnover velocity of syllable change in Spanish is around $4 \mathrm{~Hz}^{27}$. Other explanation, is that some researchers found that optimum speech intelligibility is achieved when the syllable rhythm is within the range of Theta electroencephalographic frequency $(4-7 \mathrm{~Hz})$, comparable to the rate at which segments and syllables are articulated in conversational speech ${ }^{28}$.

\section{Study limitations}

The research had a cross-sectional comparison design instead of a prospective follow-up. Of course, our general correlations do not establish causality. The number of cases studied is small, thus, in future researches, the number of studied subjects must be increased. In addition, functional magnetic 
resonance imaging or tractographic observations must be included in future studies.

In conclusion, children with PD exhibit poor skills in PA measurement and SAM than control children.
Significant correlations between PA measurement and SAM function at $4 \mathrm{~Hz}$ were found and could be the basis of the deficient language processing exhibited by children with PD.

\section{References}

1. Gersons-Wolfensberger DCM, Ruijssenaars WAJJM. Definition and treatment of dyslexia:A report by the Committee on Dyslexia of the Health Council of The Netherlands. J Learn Disabil. 1997;30(2):209-13. doi:10.1177/002221949703000208

2. Peñaloza-López YR, Poblano A, García-Pedroza F. Central auditory processing alterations in phonological dislexia. In: Costa A, Villalba E, editores. Horizons in neuroscience research. New York: Nova Science; 2013. p. 123-34.

3. Tanaka H, Black JM, Hulme C, Stanley LM, Kesler SR, Whitfield-Gabrieli S et al. The brain basis of the phonological deficit in dyslexia is independent of IQ. Psychol Sci. 2011;22(11):1442-51. doi:10.1177/0956797611419521

4. O'Brien BA, Wolf M, Lovett MW. A taxometric investigation of developmental dyslexia subtypes. Dyslexia. 2012;18(1):16-39. doi:10.1002/dys.1431

5. Thatcher Kantor P, Wagner RK, Torgesen JK, Rashotte CA. Comparing two forms of dynamic assessment and traditional assessment of preschool phonological awareness. J Learn Disabil. 2011;44(4):313-21. doi:10.1177/0022219411407861

6. Melby-Lervåg M, Lyster SA, Hulme C. Phonological skills and their role in learning to read: a meta-analytic review. Psychol Bull. 2012;138(2):322-52. doi:10.1037/a0026744

7. Wakefield GH, Viemeister NF. Discrimination of modulation depth of sinusoidal amplitude modulation (SAM) noise. J Acoust Soc Am. 1990;88(3):1367-73. doi:10.1121/1.399714

8. Banai K, Sabin AT, Wright BA. Separable developmental trajectories for the abilities to detect auditory amplitude and frequency modulation. Hear Res. 2011;280(1-2):219-27. doi:10.1016/j.heares.2011.05.019

9. Poblano A, Valadez-Tepec T, Arias ML, García-Pedroza F. Phonological and visuo-spatial working memory alterations in dyslexic children. Arch Med Res. 2000;31(5):493-6. doi:10.1016/S0188-4409(00)00096-5

10. Olivares-García MR, Peñaloza-López YR, García-Pedroza F, Pérez-Ruiz SJ, Uribe-Escamilla R, Jiménez-de-la-Sancha S. Identification of auditory laterality by means of a new dichotic digit test in Spanish, and body laterality and spatial orientation in children with dyslexia and in controls. Rev Neurol. 2005;41(4):198-205. Spanish.

11. Peñaloza-López YR, Olivares García MR, Jiménez de la Sancha S, García Pedroza F, Pérez Ruiz SJ. [Assessment of central auditory processes in Spanish in children with dyslexia and controls: binaural fusion test and filtered word test]. Acta Otorrinolaringol Espñola. 2009;60(6):415-21. Spanish. doi:10.1016/j.otorri.2009.06.002

12. American Psychiatric Association. Diagnostic and statistic manual of mental disorders. DSM-IV-R. Barcelona: Masson; 2002. [Spanish].

13. Uppstad PH, Tønnessen FE. The notion of "phonology" in dyslexia research: cognitivism-and beyond. Dyslexia. 2007;13(3):154-74. doi:10.1002/dys.332

14. Ostrosky-Solis F, Gomez-Perez ME, Matute E, Rosselli M, Ardila A, Pineda D. Neuropsi Attention and Memory: a neuropsychological test battery in Spanish with norms by age and educational level. Appl Neuropsychol. 2007;14(3):156-70. doi:10.1080/09084280701508655
15. Rosselli M, Ardila A, Navarrete MG, Matute E. Performance of Spanish/English bilingual children on a spanish-language neuropsychological battery: preliminary normative data. Arch Clin Neuropsychol. 2010;25(3):218-35. doi:10.1093/arclin/acq012

16. Sattler JM, Kuncik TM. Ethnicity, socioeconomic status, and pattern of WISC scores as variables that affect psychologists' estimates of "effective intelligence". J Clin Psychol. 1976;32(2):362-6. doi:10.1002/1097-4679(197604)32:2<362::AIDJCLP2270320233>3.0.CO;2-U

17. Fernández T, Tuset AM. Bender performance and socioeconomic status in Mexican children: a cross-cultural study. Percept Mot Skills. 2007;105(3):906-14. doi:10.2466/pms.105.3.906-914

18. Vélez van Meerbeke A, Sandoval-Garcia C, Ibáñez M, Talero-Gutiérrez C, Fiallo D, Halliday K. Validation study of human figure drawing test in a Colombian school children population. Span J Psychol. 2011;14(1):464-77. doi:10.5209/rev_SJOP.2011.v14.n1.42

19. Levitt H. Transformed up-down methods in psychoacoustics.J Acoust Soc Am. 1970;49(2):467-477. doi:10.1121/1.1912375

20. Brooks AD, Berninger VW, Abbott RD. Letter naming and letter writing reversals in children with dyslexia: momentary inefficiency in the orthographic and phonological loop in working memory. Dev Neuropsychol. 2011;36(7):847-68. doi:10.1080/87565641.2011.6064

21. Lorenzi C, Dumont A, Füllgrabe C. Use of temporal envelope cues by children with developmental dyslexia.J Speech Lang Hear Res. 2000;43(6):1367-79. doi:10.1044/jsthr.4306.1367

22. Rocheron I, Lorenzi C, Füllgrabe C, Dumont A. Temporal envelope perception in dyslexic children. Neuroreport. 2002;13(13):1683-7. doi:10.1097/00001756-200209160-00023

23. Poelmans H, Luts H, Vandermosten M, Boets, Ghesquiere P, Wouters J. Reduced sensitivity to slow-rate dynamic auditory information in children with dyslexia. Res Dev Disabil. 2011;32(6):2810-9. doi:10.1016/j.ridd.2011.05.025

24. Poelmans $H$, Luts $H$, Vandermosten $M$, Boets B, Ghesquière $P$, Wouters J. Auditory steady state cortical responses indicate deviant phonemic-rate processing in adults with dyslexia. Ear Hear. 2012;33(1):134-43. doi:10.1097/AUD.0b013e31822c26b9

25. Law JM, Vandermosten M, Ghesquiere P, Wouters J. The relationship of phonological ability, speech perception, and auditory perception in adults with dyslexia. Front Hum Neurosci. 2014;8:482. doi:10.3389/fnhum.2014.00482

26. Flaugnacco E, Lopez L, Terribili C, Zoia S, Buda S, Tilli S et al. Rhythm perception and production predict reading abilities in developmental dyslexia. Front Hum Neurosci. 2014;8:392. doi:10.3389/fnhum.2014.00392

27. Pellegrino F, Coupé C, Marisco E. A cross language perspective on speech informant rate. Language. 2011;87(3):539-58. doi:10.1353/Lan.2011.0057

28. Ghitza O, Greenberg S. On the possible role of brain rhythms in speech perception: intelligibility of time-compressed speech with periodic and aperiodic insertions of silence. Phonetica. 2009;66(12):13-126. doi:10.1159/000208934 